\title{
Evolutionary game analysis of Chinese cross border logistics enterprises adopting blockchain technology in supply chain
}

\author{
KunYang Liu ${ }^{1}$, Yong Zhang ${ }^{1, *}$ \\ ${ }^{1}$ College of Economics and Management, China Jiliang University, Hangzhou, China
}

\begin{abstract}
Blockchain technology is considered to be the representative technology of the fourth technological revolution, and logistics and supply chain field has been considered as the main application direction in the next step by industry and academia. In order to study the behavior and intention of Chinese cross-border logistics enterprises to introduce blockchain into internal supply chain, this paper constructs a model of cross-border logistics enterprises adopting blockchain technology on the basis of bounded rationality based on the game model, this paper attempts to find out the factors that affect the introduction of blockchain into the internal supply chain through mathematical derivation and numerical analysis. The game results show that the willingness of cross-border logistics enterprises to adopt blockchain is closely related to the technical ability of blockchain, the incremental performance after the introduction of blockchain, the conversion cost of blockchain technology, and other factors. Enterprises should coordinate various factors and choose to adopt blockchain technology according to their own situation.
\end{abstract}

\section{Introduction}

Blockchain technology, as an integrated and innovative product of chain data structure, distributed database, cryptography encryption, intelligent contract and other technologies, has been extended from the original financial field to other fields in recent years, such as data transaction and sharing, intellectual property management, information security. Logistics and supply chain is considered by industry and academia as the main application direction of this technology in the next few years. The core technical features of blockchain include the tamper and traceability of data, distributed accounting and storage, point-to-point transaction and decentralized architecture, automatic intelligent contracts. In the field of logistics and supply chain, the problems such as product tracking and quality assurance, poor control capability of the whole process, high risk of data and privacy leakage, and difficulty of information sharing of carrier have not been fundamentally solved. However, for cross-border logistics business with more participants, more complex processes, greater supervision difficulty, higher trust cost and transaction cost, these problems will be more prominent, especially in recent years, under the background of the rapid growth of China's digital economy and e-commerce industry, cross-border logistics industry also urgently needs to introduce new technologies to solve these problems.

Many studies have involved the application of blockchain technology in the cross-border logistics industry. Davor dujak et al. believe that blockchain has great potential for large-scale improvement. Because blockchain technology is expected to overcome the problem of trust and allow distrust, it can provide a safe and reliable logistics and supply chain information exchange system in the supply network. The supply chain is moving from blockchain to a wider range of distributed accounting technology [1]. Edvard tijan et al. studied the possibility of the development of distributed data storage technology represented by blockchain in Sustainable Logistics and supply chain management. The main problems and challenges in logistics, such as order delay, commodity damage, errors and multiple input data, can be minimized by introducing blockchain technology [2]. Hanqing $\mathrm{Wu}$ found that the traditional supply chain management mechanism has many problems, such as insufficient information sharing, long data retrieval delay, unreliable product tracking and so on. The latest development of blockchain technology shows great potential to solve these problems, because it has the characteristics of invariance, transparency and decentralization [3]. Zvonko Merka Chen et al. believe that the advantage of blockchain technology is to improve the security, speed up the transaction speed, decentralization, invariance, transparency and provide trust. The combination of blockchain technology and the Iot in logistics and transportation is conducive to business process optimization and supply chain traceability improvement of traceability and transparency and significant financial cost savings [4].

According to the general definition, blockchain can be divided into permissioned blockchain and permissionless blockchain (or public blockchain). Permissioned blockchain also includes private chain and consortium chain. A permissioned blockchain means that

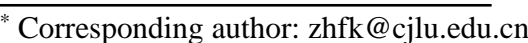


the blockchain is only open to specific entities, and certain permissions are required for data writing, reading, and modifying. The permissions of the private chain are completely owned by an entity, while the permissions of the consortium chain are jointly owned by a certain number of entities. The permissionless blockchain refers to the decentralized database, which is open to all subjects and can read and write data freely. The typical applications of permissionless blockchain include bitcoin, Ethereum, IBM Hyperledger, etc. due to its low transaction efficiency, high transaction cost, poor scalability and other problems, it is difficult to be widely used in the fields other than digital currency and finance, so in the future, the permissioned blockchain will be widely used for enterprises. This paper studies the process of cross-border logistics enterprises adopting blockchain in the internal supply chain of the organization, and does not involve different enterprises using blockchain technology in the joint supply chain. Therefore, the blockchain we mentioned below refers to the private chain in the permissioned blockchain.

From the existing research, we find that there is still a large literature gap in the research on the adoption of blockchain in China's specific industries, especially in the field of logistics and supply chain. In recent years, China's cross-border commerce and logistics industry has developed rapidly, and the application of digital technology in this industry is also very high. At the same time, China is also in the forefront of the world in the development and application of blockchain technology, but at present, China's cross-border commerce and logistics industry is developing rapidly The proportion of cross-border logistics enterprises using blockchain technology in the supply chain business is still very low, so it is necessary to study the application of blockchain technology in China's cross-border logistics enterprises under this background.

In the research on blockchain adoption in other countries or industries, most scholars use structural equation model for empirical research, and some use expert interviews for qualitative research. As the adoption and diffusion of emerging technologies in the industry level is a long-term dynamic process, game theory is a suitable analysis tool, but the assumption of complete rationality of static game is difficult to achieve, and the evolutionary game model based on partial rationality and dynamic learning of game players is more in line with the facts. Therefore, this paper constructs a dynamic model for cross-border logistics enterprises to adopt blockchain technology This paper attempts to use mathematical derivation method to explore the main factors that affect the adoption behavior of enterprises, so as to provide some reference for enterprises.

\section{Model assumption}

In the dynamic game process of cross-border logistics enterprises adopting blockchain technology, the main players of the game are cross-border logistics enterprise groups, and the evolutionary game requires that the participants should be groups of a certain scale rather than individuals, while that of Chinese cross-border logistics enterprises is consistent with this assumption. Under the market mechanism, cross-border logistics enterprises independently choose their own strategies. Due to the uncertainty of the development of blockchain technology and the incomplete and asymmetric information, the introduction of blockchain technology within the organization requires higher $\mathrm{R} \& \mathrm{D}$ and operation investment. Therefore, in the initial stage, only partially rational enterprises will not directly choose to adopt blockchain technology The adoption decisions of enterprises will change with the continuous maturity of enterprises, the change of internal and external environment of organizations and industries.

Based on the actual situation of China's cross-border logistics enterprises, we divide them into two groups: group A and group B. group a refers to enterprises with large scale and technological strength. Most of these enterprises are subsidiaries of China's large-scale ecommerce platforms or have received investment support from these companies. The business scope of enterprises includes cross-border logistics and domestic logistics; group B refers to enterprises without Supported by e-commerce platform, they only carry out crossborder logistics business. There is no absolute heterogeneity in their capabilities in cross-border logistics business. Under the market mechanism, the technology adoption decision-making behaviors of the two types of enterprises are independent. Our basic assumptions are as follows:

For whether or not to introduce blockchain technology into the internal supply chain of an organization, the strategy space of the two types of enterprises is adopt blockchain technology, not adopt blockchain technology\}. The probability of individuals in group A of enterprise choosing to adopt blockchain strategy is $\mathrm{x}(\mathrm{x} \in[0,1])$, and the probability of choosing not to adopt blockchain strategy is $1-x$. the probability of individuals in group B of enterprise choosing to adopt blockchain strategy is $\mathrm{y}(\mathrm{y} \in[0,1])$, and the probability of choosing not to adopt blockchain strategy is 1-y.

The original benefits of two types of enterprises are $\mathrm{R}_{1}$ and $\mathrm{R}_{2}$, when they do not adopt blockchain technology and traditional supply chain system, and the original costs are $C_{1}$ and $C_{2}$. The benefits obtained when choosing to adopt blockchain technology to transform the traditional supply chain network are $R_{1}+\Delta R_{1}$ and $R_{2}+\Delta R_{2}$. The comprehensive adoption costs of conversion, coordination and operation required for introducing blockchain are recorded as $\Delta \mathrm{C}_{1}$ and $\Delta \mathrm{C}_{2}$ respectively. Then the total cost of adopting blockchain technology is $\mathrm{C}_{1}+\Delta \mathrm{C}_{1}$ and $\mathrm{C}_{2}+\Delta \mathrm{C}_{2}$. It needs higher investment to transform from the past centralized supply chain architecture to multi-center blockchain architecture. In the initial stage, both $\Delta \mathrm{C}_{1}$ and $\Delta \mathrm{C}_{2}$ are relatively high. With the continuous development of technology, these costs will gradually decrease. When one enterprise adopts the blockchain technology and the other enterprise does not adopt the blockchain technology, the adopter will have a certain competitive advantage and bring potential loss of income to the other party. We 
record them as $\mathrm{L}_{1}$ and $\mathrm{L}_{2}$. When the two types of enterprises choose to introduce blockchain technology to transform the supply chain system, due to the significant differences in organizational resources, technical capabilities and talents, the ability of enterprises to develop blockchain is also different. We use $\lambda_{1}$ and $\lambda_{2}$ to represent the ability coefficient of a and B enterprises to apply blockchain Technology in the supply chain $\left(\lambda_{1} \in[0,1], \lambda_{2} \in[0,1]\right)$. Based on the above assumptions, we establish the game income matrix of two types of cross-border logistics enterprise groups adopting blockchain behavior, as shown in Table 1 .

Table 1. Revenue matrix

\begin{tabular}{ccc}
\hline $\begin{array}{c}\text { B } \\
\mathbf{A}\end{array}$ & Adopt blockchain & $\begin{array}{c}\text { Not Adopt } \\
\text { blockchain }\end{array}$ \\
\hline $\begin{array}{c}\text { Adopt } \\
\text { blockchain }\end{array}$ & $\lambda_{1}\left(\mathrm{R}_{1}+\Delta \mathrm{R}_{1}\right)-\mathrm{C}_{1}-\Delta \mathrm{C}_{1}$, & $\lambda_{1}\left(\mathrm{R}_{1}+\Delta \mathrm{R}_{1}\right)-$ \\
& $\lambda_{2}\left(\mathrm{R}_{2}+\Delta \mathrm{R}_{2}\right)-\mathrm{C}_{2}-\Delta \mathrm{C}_{2}$ & $\mathrm{C}_{1}-\Delta \mathrm{C}_{1}$, \\
& & $\mathrm{R}_{2}-\mathrm{C}_{2}-\mathrm{L}_{1}$ \\
Not Adopt & $\mathrm{R}_{1}-\mathrm{C}_{1}-\mathrm{L}_{2}$, & \\
blockchain & $\lambda_{2}\left(\mathrm{R}_{2}+\Delta \mathrm{R}_{2}\right)-\mathrm{C}_{2}-\Delta \mathrm{C}_{2}$ & $\mathrm{R}_{1}-\mathrm{C}_{1}$, \\
& & $\mathrm{R}_{2}-\mathrm{C}_{2}$ \\
\hline
\end{tabular}

\section{Model derivation and analysis}

When an individual in A-class enterprise chooses to adopt blockchain technology in the supply chain, the benefits are as follows:

$H_{A}^{1}=y\left[\lambda_{1}\left(R_{1}+\Delta R_{1}\right)-C_{1}-\Delta C_{1}\right]+(1-y)\left[\lambda_{1}\left(R_{1}+\right.\right.$ $\left.\left.\Delta R_{1}\right)-C_{1}-\Delta C_{1}\right]$

When an individual in A-class enterprise chooses not to adopt blockchain technology, the benefits are as follows:

$$
H_{A}^{2}=y\left(R_{1}-C_{1}-L_{2}\right)+(1-y)\left(R_{1}-C_{1}\right)
$$

Therefore, the average expected income of enterprises A is:

$$
H_{A}=x H_{A}^{1}+(1-x) H_{A}^{2}
$$

The dynamic equation of enterprises A adopting blockchain strategy is as follows:

$$
\begin{aligned}
& U(x, y)=\frac{d x}{d t}=x\left(H_{A}^{1}-H_{A}\right)=x(1-x)\left(H_{A}^{1}-H_{A}^{2}\right)= \\
& x(1-x)\left(\lambda_{1} R_{1}+\lambda_{1} \Delta R_{1}+y L_{2}-\Delta C_{1}-R_{1}\right)
\end{aligned}
$$

When an individual in enterprise $\mathrm{B}$ chooses to adopt blockchain technology in the supply chain, the benefits are as follows:

$H_{B}^{1}=x\left[\lambda_{2}\left(R_{2}+\Delta R_{2}\right)-C_{2}-\Delta C_{2}\right]+(1-x)\left[\lambda_{2}\left(R_{2}+\right.\right.$ $\left.\left.\Delta R_{2}\right)-C_{2}-\Delta C_{2}\right]$

When an individual in enterprise $\mathrm{B}$ chooses not to adopt blockchain technology, the benefits are as follows:

$$
H_{R}^{2}=x\left(R_{2}-C_{2}-L_{1}\right)+(1-x)\left(R_{2}-C_{2}\right)
$$

Therefore, the average expected income of enterprises B is:

$$
H_{B}=y H_{R}^{1}+(1-y) H_{R}^{2}
$$

The dynamic equation of enterprises $\mathrm{B}$ adopting blockchain strategy is as follows:

$$
V(x, y)=\frac{d y}{d t}=y\left(H_{B}^{1}-H_{B}\right)=y(1-y)\left(H_{B}^{1}-H_{B}^{2}\right)=
$$$$
y(1-y)\left(\lambda_{2} R_{2}+\lambda_{2} \Delta R_{2}+x L_{1}-\Delta C_{2}-R_{2}\right)
$$

The game process of two types of enterprises adopting blockchain behavior constitutes a twodimensional dynamic system. Let $U(x, y), V(x, y)=0$, we get five partial equilibrium points $(0,0),(0,1),(1,0)$, $(1,1),(\mathrm{x} *, \mathrm{y} *)$, Where $\mathrm{x} *$ and $\mathrm{y} *$ are respectively $\frac{\left[\Delta C_{2}+R_{2}-\lambda_{2}\left(R_{2}+\Delta R_{2}\right)\right]}{L_{1}}, \frac{\left[\Delta C_{1}+R_{1}-\lambda_{1}\left(R_{1}+\Delta R_{1}\right)\right]}{L_{2}}$.The partial equilibrium obtained by simultaneous replication of dynamic equations is not necessarily the evolutionary stability strategy(ESS) of evolutionary game, thus we need to further analyze the local stability of these five partial equilibrium points. The Jacobian matrix of the power system can be expressed as:

$$
J=\frac{\frac{\partial U(x)}{\partial x},}{\frac{\partial V(x)}{\partial x},} \frac{\frac{\partial U(x)}{\partial y}}{\partial x}=\begin{array}{ll}
a_{11} & a_{12} \\
a_{21} & a_{22}
\end{array}
$$

When the local equilibrium satisfies two conditions, trace condition $\operatorname{tr} J=a_{11}+a_{22}<0$ and determinant condition $\operatorname{det} J=a_{11} a_{22}-a_{12} a_{21}>0$, it will become an ESS. Obviously, since the trace of matrix $J$ at the point $\left(\mathrm{x}^{*}, \mathrm{y} *\right)$ is 0 , it does not meet the requirements of ESS, so the equilibrium point must not be ESS. Next, we further analyze the stability strategies of other four points. Table 2 shows the values of the four partial equilibrium points.

Table 2. J-matrix value of equilibrium point

\begin{tabular}{lllll}
\hline point & \multicolumn{1}{c}{$a_{11}$} & $a_{12}$ & $a_{21}$ & \multicolumn{1}{c}{$a_{22}$} \\
\hline$(0,0)$ & $\lambda_{1} R_{1}+\lambda_{1} \Delta R_{1}$ & 0 & 0 & $\lambda_{2} R_{2}+\lambda_{2} \Delta R_{2}$ \\
& $-\Delta \mathrm{C}_{1}-\mathrm{R}_{1}$ & & & $-\Delta C_{2}-R_{2}$ \\
& $\lambda_{1} R_{1}+\lambda_{1} \Delta R_{1}$ & 0 & 0 & $-\lambda_{2} R_{2}-\lambda_{2} \Delta R_{2}$ \\
$(0,1)$ & $+L_{2}-\Delta \mathrm{C}_{1}$ & & & $+\Delta C_{2}+R_{2}$ \\
& $-\mathrm{R}_{1}$ & & & \\
& $-\lambda_{1} R_{1}-\lambda_{1} \Delta R_{1}$ & 0 & 0 & $\lambda_{2} R_{2}+\lambda_{2} \Delta R_{2}+L_{1}$ \\
& $+\Delta \mathrm{C}_{1}+\mathrm{R}_{1}$ & & & $-\Delta C_{2}-R_{2}$ \\
$(1,0)$ & $-\lambda_{1} R_{1}-\lambda_{1} \Delta R_{1}$ & & & \\
& $-L_{2}+\Delta \mathrm{C}_{1}$ & 0 & 0 & $-\lambda_{2} R_{2}-\lambda_{2} \Delta R_{2}$ \\
& $+\mathrm{R}_{1}$ & & & $-L_{1}+\Delta C_{2}+R_{2}$ \\
\hline$(1,1)$ & & & & \\
& & & & \\
& & &
\end{tabular}

According to the trace and determinant of four points substituted into the matrix $\mathrm{J}$, the local stability of the system Jacobian matrix is analyzed, and the equilibrium results under different conditions are obtained, as shown in Table 3. For the convenience of the discussion below, We use $\alpha$ and $\beta$ express $\lambda_{1}\left(\mathrm{R}_{1}+\Delta \mathrm{R}_{1}\right)-\mathrm{R}_{1}-\Delta \mathrm{C}_{1}, \lambda_{2}\left(\mathrm{R}_{2}+\right.$ $\left.\Delta \mathrm{R}_{2}\right)-\mathrm{R}_{2}-\Delta \mathrm{C}_{2}$ respectively. Table 3 lists four possible 
evolutionary stability strategies. Next we will analyze these four points in detail.

Table 3. Analysis of evolutionary stability

\begin{tabular}{ccc}
\hline evolution state & condition & ESS \\
\hline 1 & $\alpha<0, \beta<0$ & $(0,0)$ \\
2 & $\beta-\alpha>\mathrm{L}_{2}, \alpha+\mathrm{L}_{2}<0, \alpha$ & $(0,1)$ \\
& $<0, \beta>0$ \\
3 & $\alpha-\beta>\mathrm{L}_{1}, \beta+\mathrm{L}_{1}<0, \beta$ & $(1,0)$ \\
& $<0, \alpha>0$ \\
4 & $\alpha>0, \quad \beta>0$
\end{tabular}

(1) when $\alpha+\beta<0, \alpha<0, \beta<0$, the evolutionary stability strategy of the system is $(0,0)$. In order to verify our derivation and show the evolution trend more intuitively, we use MATLAB software to simulate the game process. Under the condition of this situation, we assign values to the parameters, substituting numerical simulation, as shown in Figure 1, the final evolution is that the probability of class A enterprises and class B enterprises finally adopting blockchain technology will be close to 0 . (the specific parameter values are $\lambda_{1}=0.2, \mathrm{R}_{1}=100, \Delta \mathrm{R}_{1}=10, \mathrm{C}_{1}=20, \Delta \mathrm{C}_{1}=30, \mathrm{~L}_{1}=10$, $\lambda_{2}=0.1, \mathrm{R}_{2}=60, \Delta \mathrm{R}_{2}=4, \mathrm{C}_{2}=10, \Delta \mathrm{C}_{2}=15, \mathrm{~L}_{2}=10$ )

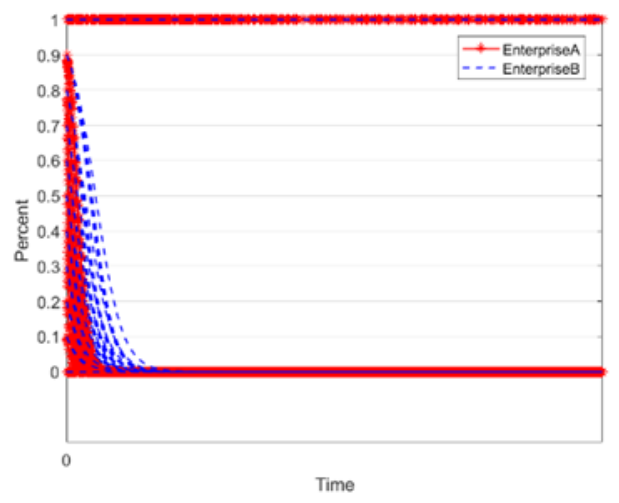

Fig. 1. point $(0,0)$ simulation results

(2) when $\beta-\alpha>L_{2}, \alpha+L_{2}<0, \alpha<0, \beta>0$, the evolutionary stability strategy of the system is $(0,1)$. Under the condition of this situation, we assign values to the parameters, substituting numerical simulation, as shown in Figure 2, the final evolution situation is that the probability of class A enterprises adopting blockchain technology tends to 0 , and the probability of class B enterprises adopting blockchain technology tends to 1 . (the specific parameter values are

$\lambda_{1}=0.5, \mathrm{R}_{1}=100, \Delta \mathrm{R}_{1}=20, \mathrm{C}_{1}=20, \Delta \mathrm{C}_{1}=20, \mathrm{~L}_{1}=10$,

$\lambda_{2}=0.2, \mathrm{R}_{2}=60, \Delta \mathrm{R}_{2}=10, \mathrm{C}_{2}=10, \Delta \mathrm{C}_{2}=30, \mathrm{~L}_{2}=10$ )

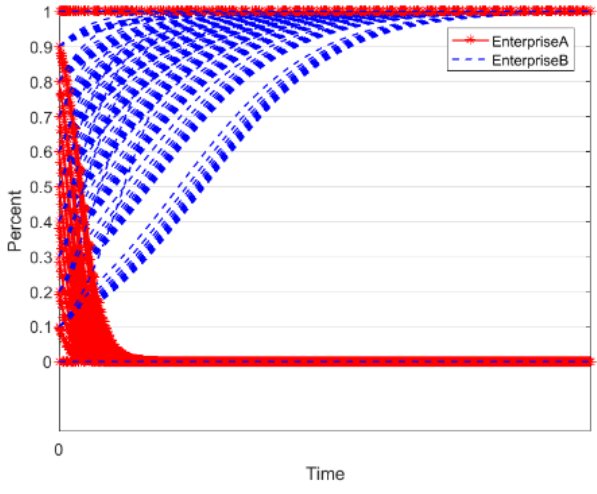

Fig. 2. piont $(0,1)$ simulation results

(3) when $\alpha-\beta>L_{1}, \beta+L_{1}<0, \beta<0, \alpha>0$, the evolutionary stability strategy of the system is $(1,0)$. Under the condition of this situation, we assign values to the parameters, substituting numerical simulation, as shown in Figure 3. The final evolution is that the probability of class A enterprises adopting blockchain technology tends to be 1 , and the probability of class B enterprises adopting blockchain technology tends to be 0 . (the specific parameter values are

$\lambda_{1}=0.5, \mathrm{R}_{1}=100, \Delta \mathrm{R}_{1}=20, \mathrm{C}_{1}=20, \Delta \mathrm{C}_{1}=20, \mathrm{~L}_{1}=10$, $\lambda_{2}=0.1, \mathrm{R}_{2}=60, \Delta \mathrm{R}_{2}=4, \mathrm{C}_{2}=10, \Delta \mathrm{C}_{2}=15, \mathrm{~L}_{2}=10$ )

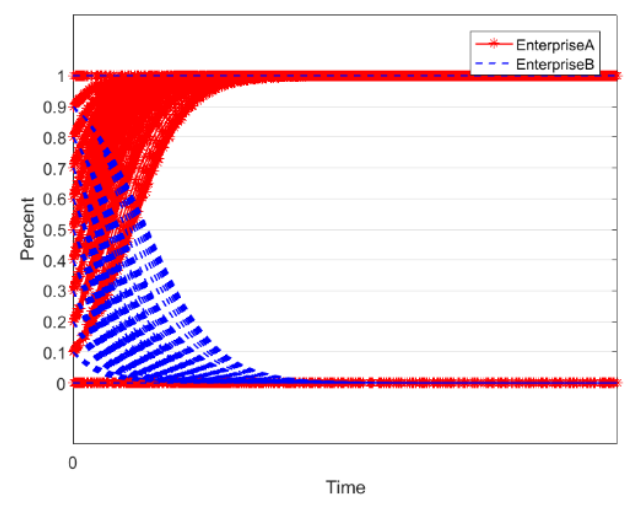

Fig. 3. piont $(1,0)$ simulation results

(4) when $\alpha>0, \beta>0$, the evolutionary stability strategy of the system is $(1,1)$. Under the condition of this situation, we assign values to the parameters, substituting numerical simulation, as shown in Figure 4, the final evolution situation is that the probability of adopting blockchain technology for class A enterprises and class B enterprises will be close to 1 . This is an ideal situation for us to promote the application of blockchain technology at the industry level. In order to achieve this evolution state, the net income value of two types of enterprises after adopting blockchain technology needs to be high enough, the technical ability needs to be strong enough, and the technology conversion cost needs to be low enough. (the specific parameter values are $\lambda_{1}=0.7, \mathrm{R}_{1}=100, \Delta \mathrm{R}_{1}=50, \mathrm{C}_{1}=20, \Delta \mathrm{C}_{1}=10, \mathrm{~L}_{1}=10$, $\lambda_{2}=0.4, R_{2}=60, \Delta R_{2}=20, C_{2}=10, \Delta C_{2}=2, L_{2}=10$ ) 


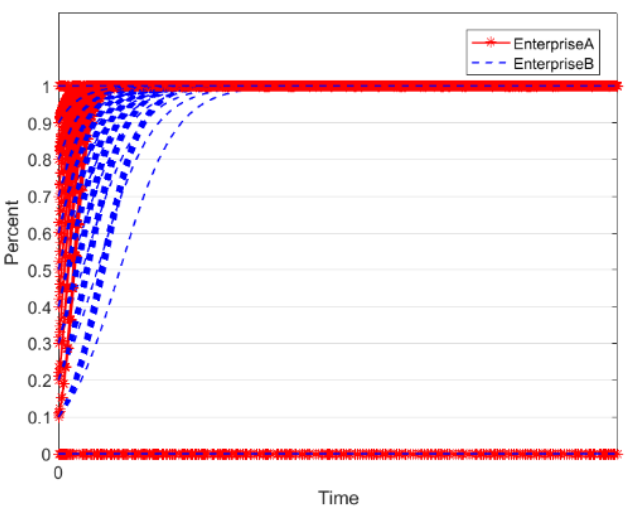

Fig. 4. piont $(1,1)$ simulation results

\section{Conclusion and Prospection}

This paper analyzes the dynamic evolution game process of the adoption of blockchain technology in the supply chain of the organization by cross-border logistics enterprises in the market mechanism. The research finds that the benefit added value, the cost of developing and transforming the operation blockchain and the technical capability of the enterprise will significantly affect the organization's adoption of block chain technology in the internal supply chain, whether it is the combination of ecommerce business or the single cross-border logistics enterprise. In order to realize the large-scale application of blockchain technology in China's cross-border logistics enterprises, these factors must be considered first by the enterprises under the market mechanism. In terms of how to improve the technical capability of enterprises, whether to independently develop and operate blockchain system, or to adopt existing open source platform or cooperate with other enterprises to develop, this requires enterprises to choose according to their own actual situation. In terms of cost, in addition to technical cost, the internal allocation of resources for new and old technologies and the staff's allocation of traditional technology are required The effect of dependence on new technology resistance will have a great impact on the cost of adopting blockchain. In terms of performance increase, how to ensure the expected revenue after blockchain technology is used in the supply chain is of great importance. If the enterprise adopts blockchain technology in the absence of mature solutions, it may make the adoption of blockchain technology The increase in benefits is limited.

For a diffusion process of technological innovation, the diffusion of technology under market mechanism is only the basic situationLearning from the development experience of similar technologies in the past, the government's regulation and incentive behavior will significantly change the application speed of technological innovation. In addition, for the crossborder logistics industry, due to the rapid growth of the number of emerging middle-income groups in China and the change of consumers' consumption concept, consumers' preference for technology choice will also affect the technology adoption decisions of enterprises due to the demand for high-quality logistics services. In the future research, we can further analyze the evolution process of the adoption of blockchain technology in the supply chain of China's cross-border logistics industry under government incentives and consumer preferences.

\section{References}

1. Dujak D., Sajter D. (2019) Blockchain Applications in Supply Chain. In: Kawa A., Maryniak A. (eds) SMART Supply Network. EcoProduction (Environmental Issues in Logistics and Manufacturing). Springer, Cham. 21-46.

2. Tijan, E. , Aksentijević, Saša, Ivanić, Katarina, \& Jardas,M.(2019). Blockchain technology implementation in logistics. Sustainability, 11(4).

3. Wu, H. , Cao, J. , Yang, Y. , Tung, C. L. , Jiang, S. , \& Tang, B. , et al. (2019). Data Management in Supply Chain Using Blockchain: Challenges and a Case Study. 2019 28th International Conference on Computer Communication and Networks (ICCCN). IEEE.

4. Merka, Z., D Perkov, \& Bonin, V. . (2020). The significance of blockchain technology in digital transformation of logistics and transportation. International Journal of E-Services and Mobile Applications, 12(1), 1-20. 